\title{
Effectiveness of Beauveria bassiana Native Isolates in the Biological Control of the Mediterranean Fruit Fly (Ceratitis capitata)
}

\author{
Fadi Othman Qazzaz, Mohammad Ibrahim Al-Masri, Radwan Mahmoud Barakat* \\ Plant Protection Research Centre, College of Agriculture, Hebron University, Hebron, Palestine \\ Email: ${ }^{*}$ radwanb@hebron.edu
}

Received 2 March 2015; accepted 8 April 2015; published 9 April 2015

Copyright () 2015 by authors and Scientific Research Publishing Inc.

This work is licensed under the Creative Commons Attribution International License (CC BY). http://creativecommons.org/licenses/by/4.0/

c) (i) Open Access

\section{Abstract}

The effectiveness of native entomopathogenic Beauveria bassiana isolates in the biological control of the Mediterranean fruit fly (Ceratitis capitata) was evaluated under laboratory and field conditions. Local isolates (P. Bv32, P. Bv39, P. Bv41, P. Bv51, and P. Bv52) of the fungus B. bassiana induced higher adult mortalities $(77 \%, 65 \%, 65 \%, 65 \%$, and $58 \%$, respectively) than a control against the Mediterranean fruit fly under laboratory conditions. Adult mortality increased by increasing the conidial concentrations. In addition, the lethal time $\left(\mathrm{LT}_{50}\right)$ for killing adult $C$. capitata ranged from 3.91 to 5.60 days, and the logged lethal concentration $\left(\mathrm{LC}_{50}\right)$ ranged from 3.80 to 10.50 , depending on the isolate. Furthermore, the contact application method induced significantly higher mortality than feeding alone, compared with the control. In addition, spraying peaches with a conidial suspension of the isolates $P$. Bv32 and $P$. Bv39 significantly reduced infestation by the fruit fly, compared with the control. The isolates grew well at a temperature range of $25^{\circ} \mathrm{C}-30^{\circ} \mathrm{C}$; germination of the conidia occurred at $15^{\circ} \mathrm{C}-30^{\circ} \mathrm{C}$, and sporulation occurred at $20^{\circ} \mathrm{C}-25^{\circ} \mathrm{C}$. High Mediterranean fruit fly mortalities were induced at $15^{\circ} \mathrm{C}-30^{\circ} \mathrm{C}$, with significant differences among the isolates. However, the isolates failed to grow, germinate, or sporulate above $35^{\circ} \mathrm{C}$ or below $10^{\circ} \mathrm{C}$. Under field conditions, a formula of the bioinsecticide containing the isolate P. Bv32 of $B$. bassiana significantly reduced peach infestation with Medfly maggots by $25 \%$ compared with the control, and by $30 \%$ when combined with a low dose of the commercial insecticide Confidor ${ }^{\circledR}$.

\section{Keywords}

Beauveria bassiana, Ceratitis capitata, Entomopathogenic, Mediterranean Fruit Fly

\footnotetext{
${ }^{*}$ Corresponding author.
}

How to cite this paper: Qazzaz, F.O., Al-Masri, M.I. and Barakat, R.M. (2015) Effectiveness of Beauveria bassiana Native Isolates in the Biological Control of the Mediterranean Fruit Fly (Ceratitis capitata). Advances in Entomology, 3, 44-55. 


\section{Introduction}

The Mediterranean fruit fly (Medfly) (Ceratitis capitata, Wiedemann, 1824; Diptera, Tephritidae) is a serious global pest, particularly in the Mediterranean and Middle East regions. The insect was first detected in orchards in the area in the early 1900s [1]. It is highly polyphagous, and causes damage to a wide range of unrelated fruit crops. In the Mediterranean region, it is particularly damaging to citrus, plums, peaches, and apples. It also transmits fruit-rotting fungi [2]. An economic feasibility study conducted in 1997 showed that in Israel, Jordan, and Palestine the total annual losses from Medfly amounted to nearly US $\$ 300$ million, including the loss of markets that discriminate against Medfly and pesticide residues. In Jordan, $90 \%$ of pears, $52 \%$ of apples, and $35 \%$ of figs are infested with this species [3]. Efforts have been made to reduce the use of harmful insecticides and apply safer, alternative methods to control the Medfly. Among these are the mass-trapping technique [4], the sterile insect technique [5], and biological control using several bioagents, including the entomopathogenic fungus Beauveria bassiana ([Balsamo]; Phylum Ascomycota, Cordycipitaceae) [6] [7]. B. bassiana is the natural enemy of a wide range of insects and arachnids, and has a wide distribution [8] [9]. It acts as a control agent of several insect species worldwide, including Helicoverpa armigera (Hübner), Alphitobius diaperinus (Panzer), Plutella xylostella (Linnaeus), Laniifera cyclades, Prostephanus truncatus (Horn), Polyphagotarsonemus latus (Banks), and Bemisia tabaci (Gennadius) [10]. In addition, B. bassiana has been extensively exploited for the field control of the coffee berry borer, Hypothenemus hampei (Ferrari), in many countries around the world [11]. Review of impact of various biocontrol agents including B. bassiana on various insect species was provided [12]. Although first recognized as an insect pathogen, $B$. bassiana can exist endophytically in many wild and cultivated plant species [13], and its colonization of several herbaceous and woody species may provide a degree of bio-protection to the hosts [14]-[16]. The safety of B. bassiana as a bio-control organism has been evaluated based on its impact on non-target insects and mammals, including humans with no safety concerns identified so far [17].

There is great potential for the use of $B$. bassiana in biological control, because it can be cost-effective to locally mass-produce. Moreover, many strains are also already commercially available. B. bassiana has been mass-produced on different solid substrates, including steamed rice [18] [19].

The objective of the current study was to evaluate the effectiveness of native Palestinian B. bassiana strains in biological control of the Medfly.

\section{Materials and Methods}

\subsection{B. bassiana Isolates}

The five isolates of B. bassiana (P.Bv32, P. Bv39, P. Bv41, P. Bv51, and P. Bv52) used in the experiments were previously selected from a long screening program of 58 isolates, which were collected from 225 composite soil samples from different vegetable and crop fields on the West Bank (54 from Jenin, 23 from Hebron, 120 from Jericho and the Jordan valley, 16 from Tulkarem, and 12 from Qalqelyia).

\subsection{Rearing C. Capitata on an Artificial Diet}

Medfly cultures were established by collecting larvae from infested peaches. Neonates were reared on an artificial larval wheat bran based diet. The diet ingredients constituted $400 \mathrm{~g}$ of wheat bran, $120 \mathrm{~g}$ of brewer's yeast (Lewis Labs, USA), $180 \mathrm{~g}$ of sucrose, $0.6 \mathrm{~g}$ of Nipagin ${ }^{\mathrm{TM}}$ (Clariant, UK), $24 \mathrm{~mL}$ of $\mathrm{HCl}(32 \%)$, and $760 \mathrm{~mL}$ of water, which were mixed and kept in a refrigerator at $4^{\circ} \mathrm{C}$ to be used later in the experiments. The larvae were then transferred to $150-\mathrm{mm}$ glass plates containing the larval bran diet. The plates were kept in a plastic container containing fine vermiculite, on which the larvae could jump and pupate inside and incubated in growth chamber at $25^{\circ} \mathrm{C}$ and $90 \%$ relative humidity. Ten days later, the vermiculite was sieved using a 2-mm sieve and the collected pupae were transferred to plastic Petri dishes $\left(90 \mathrm{~mm}\right.$ in diameter) and incubated at $25^{\circ} \mathrm{C}$ and $90 \%$ relative humidity for 10 days. Pupal plates were then transferred to the adult plastic containers for emergence, after 10 days. Adult females started laying eggs 4 days after emerging. Adults were reared in closed white plastic boxes $(20 \times 40 \times 30 \mathrm{~cm})$ with circular openings covered with mesh at the front and back; the containers contained moistened cotton with the adult's cake diet (one part brewer's yeast mixed with four parts sugar as a cake). Glass plates $\left(15 \mathrm{~cm}\right.$ diameter $\times 2.5 \mathrm{~cm}$ depth, Steriplan ${ }^{\circledR}$, UK) filled with $50 \mathrm{~mL}$ of sterile distilled water (SDW) were placed under the openings at the bottom of the boxes. Adult females extended their ovipositors 
through the mesh openings and laid eggs. The eggs then fell onto a glass plate filled with water. The eggs were then collected using a 5-mL pipette and filtered in a cheese cloth for $2-3$ days. The cheese cloth containing eggs was then placed on a glass plate $(150 \mathrm{~mm}$ in diameter) with the larval diet. Plates were then covered and incubated at $25^{\circ} \mathrm{C}$ for 10 days until the eggs hatched. The plates containing larvae were placed into larger plastic containers $(40 \times 30 \times 25 \mathrm{~cm})$ that contained fine vermiculite, and the covers were removed to allow the larvae to jump into the vermiculate and pupate inside.

\subsection{Effect of Temperature on Growth Parameters}

The growth rate, sporulation, and conidial germination of all of the B. bassiana isolates were evaluated under7 temperatures. The mycelium growth rate was evaluated by inoculating glucose peptone agar (GPA) medium plates with a single spore collected from a 21-day-old culture of each fungal isolate. Five plates for each isolate were then incubated under different temperatures: $5^{\circ} \mathrm{C}, 10^{\circ} \mathrm{C}, 15^{\circ} \mathrm{C}, 20^{\circ} \mathrm{C}, 25^{\circ} \mathrm{C}, 30^{\circ} \mathrm{C}$, or $35^{\circ} \mathrm{C}$ under continuous light conditions. The fungal colony diameter was measured 4 and 7 days after inoculation. The experiment was completely randomized, with five replicates. The rate of increase in diameter was calculated by the formula: Rate $=\mathrm{D} 2-\mathrm{D} 1 / \mathrm{T} 2-\mathrm{T} 1$, where D2 and T2 were diameter and time for the second reading (at 7 days) and D1 and T1 were diameter and time for the first reading of the growth diameter (at 4 days), respectively.

The conidial germination of the isolates was evaluated by harvesting the conidia of each fungal isolate from 21-day-old cultures in $3 \mathrm{~mL}$ of SDW. The conidial concentrations were set at 700 conidia $\cdot \mathrm{mL}^{-1}$. For each isolate, $500 \mu \mathrm{L}$ of the above concentration was spread on five GPA medium plates and incubated at $5^{\circ} \mathrm{C}, 10^{\circ} \mathrm{C}, 15^{\circ} \mathrm{C}$, $20^{\circ} \mathrm{C}, 25^{\circ} \mathrm{C}, 30^{\circ} \mathrm{C}$, or $35^{\circ} \mathrm{C}$ under continuous light. The experiment was completely randomized, with five replicates per treatment. The number of colonies was recorded 5 days after inoculation.

For sporulation (conidia production), three 90-mm-diameter plates of GPA medium were inoculated with mycelial discs ( $5 \mathrm{~mm}$ ) of each $B$. bassiana isolate taken from 21-day-old cultures. Plates were incubated under continuous light at various temperatures $\left(10^{\circ} \mathrm{C}, 15^{\circ} \mathrm{C}, 20^{\circ} \mathrm{C}, 25^{\circ} \mathrm{C}\right.$, or $\left.30^{\circ} \mathrm{C}\right)$. After 21 days, mycelial disks $(0.5$ $\mathrm{cm}$ in diameter) were taken from each plate (replicate) and vortexed in $5 \mathrm{~mL}$ of $95 \%$ ethyl alcohol. A haemocytometer $\left(\right.$ abcam $^{\circledR}$, Cambridge MA, USA) was used to determine spore production per unit area of the plate. The experiment was completely randomized, with three replicates.

\subsection{Screening the Virulence of $B$, bassiana Isolates}

The conidia of all five $B$. bassiana isolates were harvested from 21-day-old cultures. Twenty mg of collected dry conidia were then placed in a test tube. Twenty adult fruit flies ( 5 - 10 days old) were placed inside each test tube and gently shaken for two minutes to inoculate the flies with conidia. The inoculated fruit flies were then transferred to plastic containers, as described above. The plastic containers were supplied with a piece of moistened cotton, which contained a small amount of adult food, and incubated at $25^{\circ} \mathrm{C} \pm 1{ }^{\circ} \mathrm{C}$. The flies were supplied with water and food on a daily basis, and any mortalities were recorded daily. The experimental design was completely randomized, with five replicates for each isolate and 20 adult fruit flies in each replicate; the experiment was repeated twice.

\subsection{The Effect of Temperature on the Virulence of B. bassiana against Adult C. capitata Flies}

The effect of temperature on the virulence of the B. bassiana isolates P. Bv32, P. Bv39, and P. Bv51 was evaluated. The conidia were harvested as described above, from 21-day-old cultures. The conidial concentration was set at $1 \times 10^{8}$ conidia $/ \mathrm{mL}$. A volume of $0.5 \mathrm{~mL}$ of the conidial suspension was suspended into each test tube for each isolate. A total of 20 flies (5 - 10 days old), were added to each test tube and were gently mixed for 20 seconds, before being transferred to plastic containers. The plastic containers were incubated in five incubators set at different temperatures $\left(10^{\circ} \mathrm{C}, 15^{\circ} \mathrm{C}, 20^{\circ} \mathrm{C}, 25^{\circ} \mathrm{C}\right.$, or $\left.30^{\circ} \mathrm{C}\right)$. The number of dead flies was recorded daily. The experimental design was completely randomized, with three replicates per isolate; the experiment was repeated twice.

\subsection{Effect of the B. bassiana Inoculum (Conidia) Concentration on Fruit Fly Mortality}

The conidia of all the B. bassiana isolates were harvested from 21-day-old cultures. Conidial concentrations 
were set at $10^{5}, 10^{6}, 10^{7}$, or $10^{8}$ conidia/mL, in addition to a control treatment that only had SDW. A $0.5-\mathrm{mL}$ aliquot of each concentration was suspended in a test tube. A total of 20 adult fruit flies (5 - 10 days old) were placed in the test tube and gently shaken with the conidial inoculum for 20 seconds. The flies were then transferred to plastic containers and incubated at $25^{\circ} \mathrm{C}$. The number of dead flies was recorded daily. The experiment was completely randomized, with three replicates for each treatment; the experiment was repeated twice.

\subsection{Method of Application}

Two methods of $B$. bassiana application (feeding and contact) were evaluated against adult $C$. capitata flies. For the feeding method, conidia were harvested with $3 \mathrm{~mL}$ of SDW from 21-day-old cultures. The conidial concentration was set at $1 \times 10^{8}$ conidia/mL. A $0.5-\mathrm{mL}$ aliquot of the suspension was mixed with $1 \mathrm{~g}$ of the adult flies' diet, and placed on a piece of cotton inside the plastic container. A total of 20 adult flies ( 5 - 10 days old) were placed in the container and incubated at $25^{\circ} \mathrm{C}$.

For the contact method, the same conidial suspension was used and $0.5 \mathrm{~mL}$ of the inoculum was suspended in a test tube. A total of 20 adult flies of the same age (5 - 10 days old) were added to the test tube, gently mixed, and placed in a plastic container containing the adult flies' diet; this was considered to be a replicate for each isolate. The plastic containers were then incubated at $25^{\circ} \mathrm{C}$ for 10 days. Fly mortality was recorded daily. The experiment was completely randomized, with three replicates for each treatment; the experiment was repeated twice.

\subsection{Bioassay on Peaches}

The ability of $B$. bassiana to control $C$. capitata infestations on peaches was tested. Isolate conidia ( $\mathrm{P}$. Bv32 and P. Bv39) were harvested with $3 \mathrm{~mL}$ of SDW from 21-day-old cultures of B. bassiana. The conidial concentration was set at $1 \times 10^{8}$ conidia/mL. Ten fully ripened peaches were sprayed with the conidial suspension of each isolate until saturation, and left for 1 hour to dry. A control set of 10 peaches was sprayed with SDW. Peach fruits were then randomly placed in plastic containers $(40 \times 50 \times 40 \mathrm{~cm})$ that were ventilated from the upper side. The containers included moistened cotton containing the Medfly's adult diet placed in 50 mm Petri plates. A total of 15 ovipositing adult Medfly females and six adult males were placed in each container. The containers were incubated at $25^{\circ} \mathrm{C}$ under normal light conditions. After 7 days, the infestation percentage and the number of Medfly larval infestations per peach were counted. The experimental design was completely randomized, with three replicates per treatment and 10 peaches per replicate; the experiment was repeated twice.

\subsection{Formulation and Field Application}

The isolate P. Bv32 was simply formulated as an emulsifiable suspension of mycoinsecticide that contained $10 \%$ dry conidia (w/v). The fungus was grown on GPA medium, and the dry conidia were harvested from 21-day-old cultures. The inert ingredients were prepared by mixing $460 \mathrm{~mL}$ of corn oil and $500 \mathrm{~mL}$ of SDW supplemented with $40 \mathrm{~mL}$ Tween ${ }^{\mathrm{TM}} 20$ per litre as an emulsifier agent (Sigma, Germany); the mixture was then homogenized (Polytron ${ }^{\circledR}$ PT 3100). The dry conidia $(10 \%$, w/v) were then added to the emulsifiable suspension, and the mixture was evenly homogenized. The formula was tested against the Medfly on 10-year-old peach trees at the AlAroub Agricultural Experimental Station (10 km north of Hebron). The field experimental design was a randomized complete block design, with four replicates (trees) for each treatment and four blocks. There were four treatments: a control (CK), in which the plants were only sprayed with SDW; an emulsifiable suspension of the bioinsecticide containing $B$. bassiana $\left(\mathrm{P}\right.$. Bv32) at a concentration of $2 \times 10^{8}$ conidia $/ \mathrm{mL}$; a commercial insecticide (Confidor ${ }^{\circledR} 350 \mathrm{SC}$, Bayer) at the recommended concentration of $0.5 \mathrm{~mL} \cdot \mathrm{L}^{-1}$; and a combination of a low dose of Confidor ${ }^{\circledR}$ at a concentration of $0.2 \mathrm{~mL} \cdot \mathrm{L}^{-1}$ and the $B$. bassiana bioinsecticide formulated earlier at a concentration of $2 \times 10^{8}$ conidia/mL, applied after 6 hours from spraying the insecticide in an integrated approach. The trees were sprayed three times, from 1 May to 30 June (2013), with a 3-week interval. Fully ripened peaches were harvested, and the Medfly infestation percentages were recorded. The experiment was repeated the following year (Figure 1).

\subsection{Statistical Analysis}

Data from all of the experiments were statistically analysed using a one-way analysis of variance (ANOVA), 


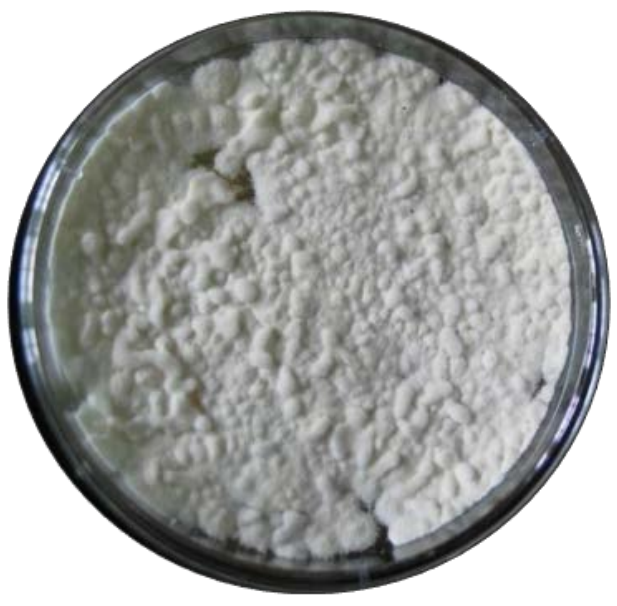

(a)

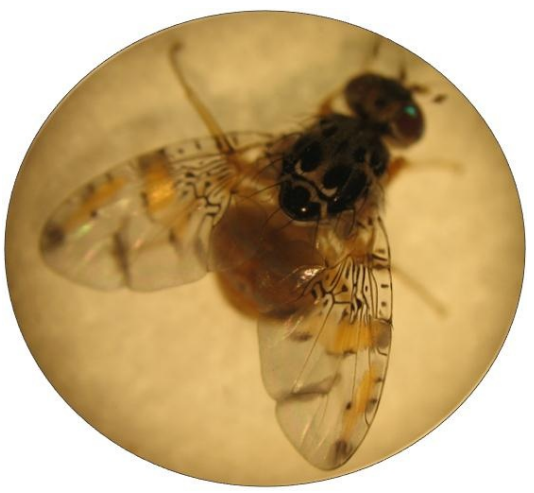

(c)

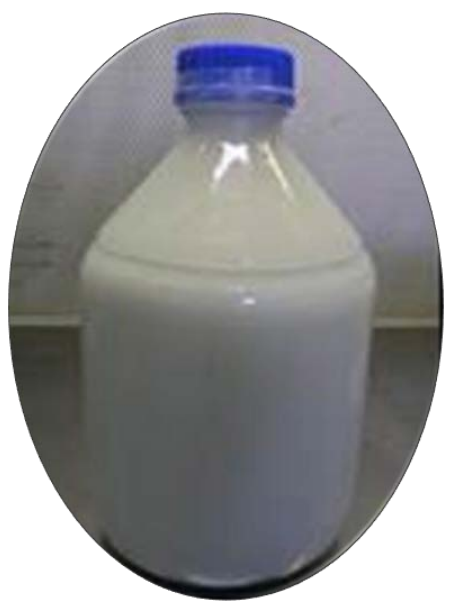

(b)

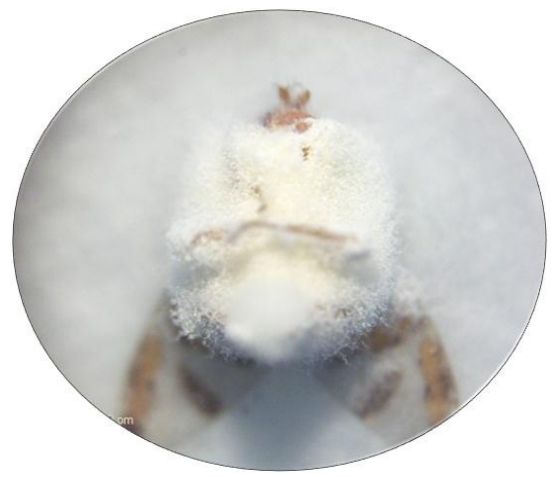

(d)

Figure 1. Culture of Beauveria bassiana native isolate P. Bv32 grown on glucose peptone agar medium (a); a formula of the bioinsecticide containing the fungus (b); a healthy adult Ceratitiscapitata fly (c); infection symptoms on an adult fly induced by a formula of the bioinsecticide containing the B. bassiana isolate P. Bv32 (d).

and a Fisher Least Significant Difference (LSD) test was used for significance testing $(\mathrm{P} \leq 0.05)$, using the Sigma Stat ${ }^{\circledR} 2.0$ program (SPSS Inc., USA).

\section{Results}

\subsection{Effect of Temperature on Growth Parameters and Mortality}

All of the $B$. bassiana isolates were able to grow in a wide temperature range $\left(10^{\circ} \mathrm{C}-30^{\circ} \mathrm{C}\right)$. The optimum temperature for mycelial growth in all of the isolates was $25^{\circ} \mathrm{C}-30^{\circ} \mathrm{C}$. All of the isolates failed to grow at temperatures below $10^{\circ} \mathrm{C}$ or above $30^{\circ} \mathrm{C}$, and there were no significant differences between the five isolates in this respect (Figure 2(a)).

The B. bassiana isolate conidia were produced and germinated in a narrow temperature range $\left(15^{\circ} \mathrm{C}-30^{\circ} \mathrm{C}\right)$, but failed to germinate at temperatures below $15^{\circ} \mathrm{C}$ or above $30^{\circ} \mathrm{C}$. The optimum temperature for germination was in the range $20^{\circ} \mathrm{C}-25^{\circ} \mathrm{C}$, without any significant differences found between the isolates (Figure 2(b)). The number of conidia produced ranged from $19 \times 10^{7}$ to $67 \times 10^{7}$ conidia/ $\mathrm{cm}^{2}$ under light conditions. The optimum temperature for sporulation was $25^{\circ} \mathrm{C}$. Conidial production decreased at $30^{\circ} \mathrm{C}$ in all the isolates and completely stopped at $35^{\circ} \mathrm{C}$, with obvious variation between the isolates (Figure 2(c)).

Temperature significantly (LSD $=9.6, \mathrm{P} \leq 0.05$ ) affected fly mortality (Figure 2(d)); the isolate P. Bv32 induced high mortality rates $(77 \%-100 \%)$ under a wide range of incubation temperatures $\left(15^{\circ} \mathrm{C}-30^{\circ} \mathrm{C}\right)$. The other isolates, however, exhibited greater infectivity only at high temperatures $\left(25^{\circ} \mathrm{C}-30^{\circ} \mathrm{C}\right.$; e.g. P. Bv39 and P. Bv51). 


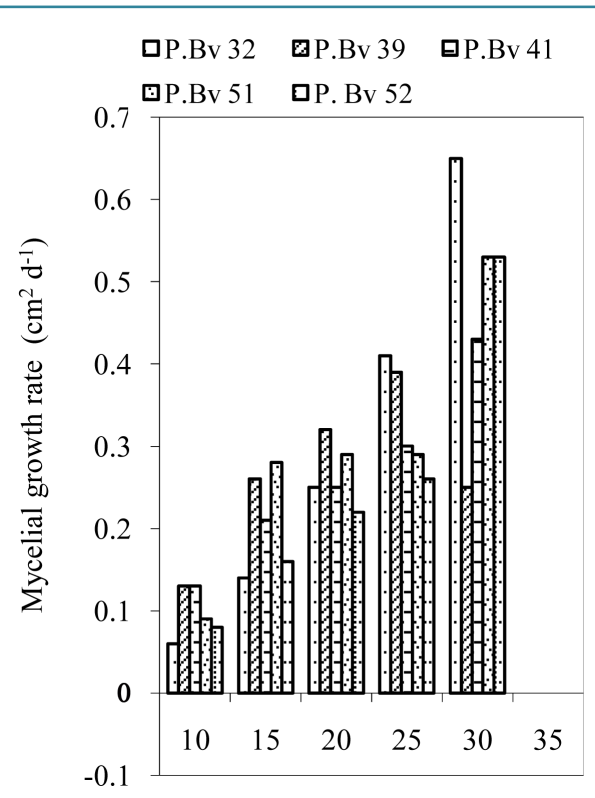

(a)

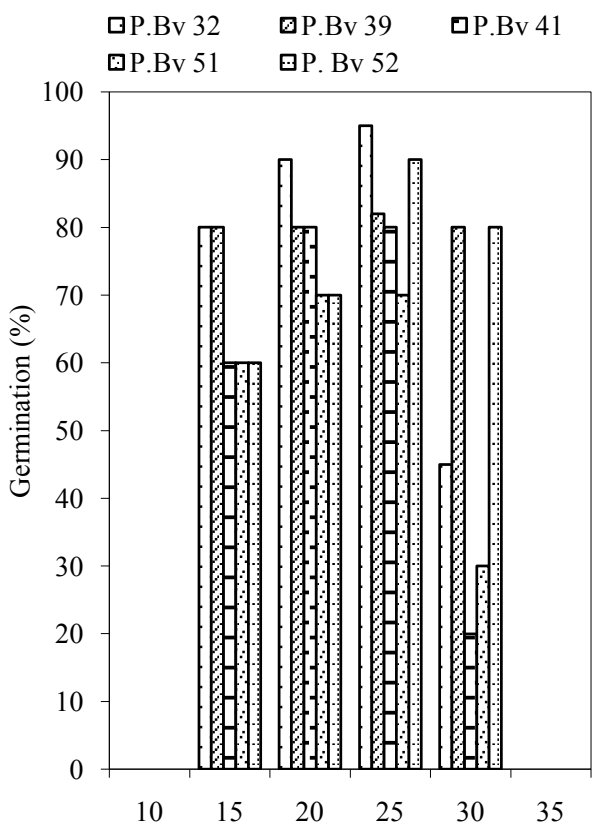

(c) $\square P . B v 32 \quad \square P . B v 39 \quad \square P . B v 41$

ㅁ. $\mathrm{P} . \mathrm{Bv} 51$ ․ $\mathrm{P} . \mathrm{Bv} 52$

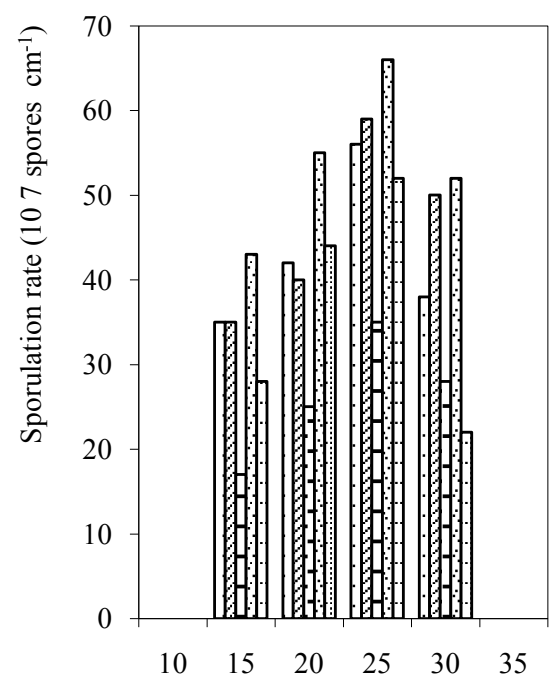

(b)
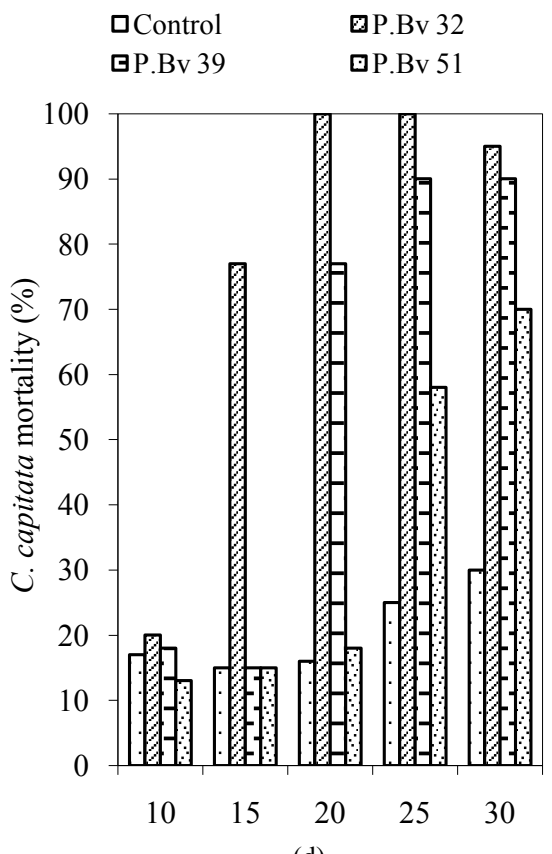

(d)

Temperature $\left({ }^{\circ} \mathrm{C}\right)$

Figure 2. Effect of temperature on Beauveria bassiana (P. Bv32, P. Bv39, P. Bv52, P. Bv41, and P. Bv51) mycelial growth rate (a) (Least Significant Difference $=0.11)$; germination (b) $(\mathrm{LSD}=9.46)$; sporulation $(\mathrm{c})(\mathrm{LSD}=8.5)$; virulence $(\mathrm{d})(\mathrm{LSD}=9.6)$.

\subsection{Virulence of $B$, Bassiana Isolates}

All of the isolates induced significant $(\mathrm{LSD}=8.3, \mathrm{P} \leq 0.05)$ mortalities $(77 \%, 65 \%, 65 \%, 65 \%$, and $58 \%$ for $\mathrm{P}$. Bv32, P. Bv39, P. Bv41, P. Bv51, and P. Bv52, respectively) within the C. capitata adult population compared to the control at the highest inoculum concentration $\left(10^{8}\right.$ conidia/mL) (Figure 3$)$. Mortality rates decreased with decreasing concentrations of $B$. bassiana conidial inoculum. At the lowest conidial concentration used $\left(10^{5}\right)$, the mortalities induced significantly (LSD $=14.64, \mathrm{P} \leq 0.05)$ by $\mathrm{P} . \mathrm{Bv} 32, \mathrm{P} . \mathrm{Bv} 39, \mathrm{P} . \mathrm{Bv} 41, \mathrm{P} . \mathrm{Bv} 51$, and P. Bv52 were $78 \%, 43 \%, 30 \%, 35 \%$, and $30 \%$, respectively (Figure 4(a)). However, at the highest concentration tested 


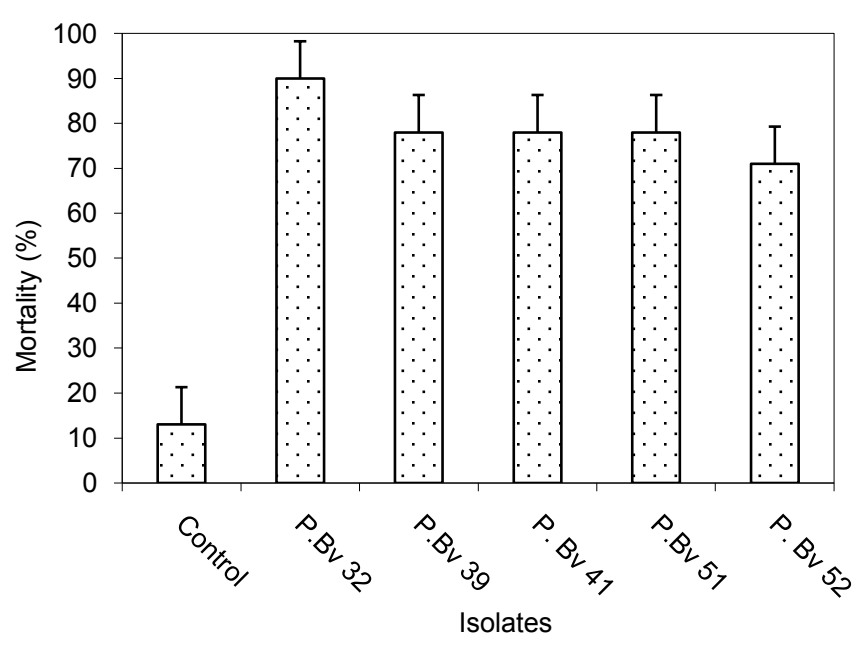

Figure 3. Adult mortality in Ceratitis capitata induced by Beauveria bassiana isolates at a concentration of $10^{8}$ conidia/mL 7 days after inoculation (Least Significant Difference $=8.3$ ).

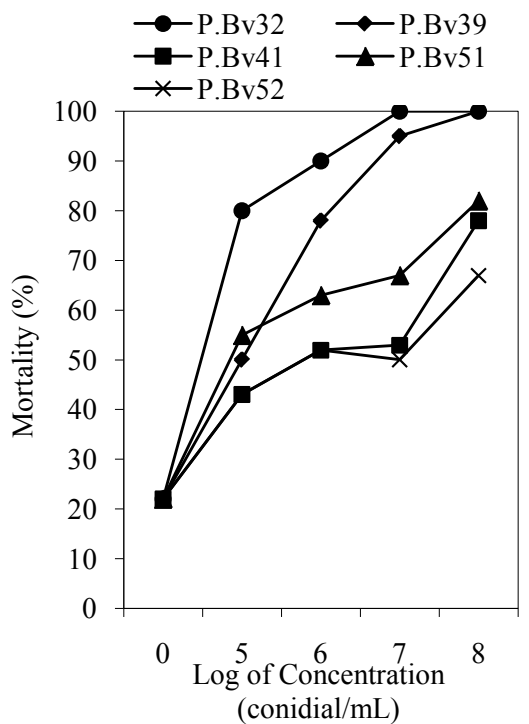

(a)

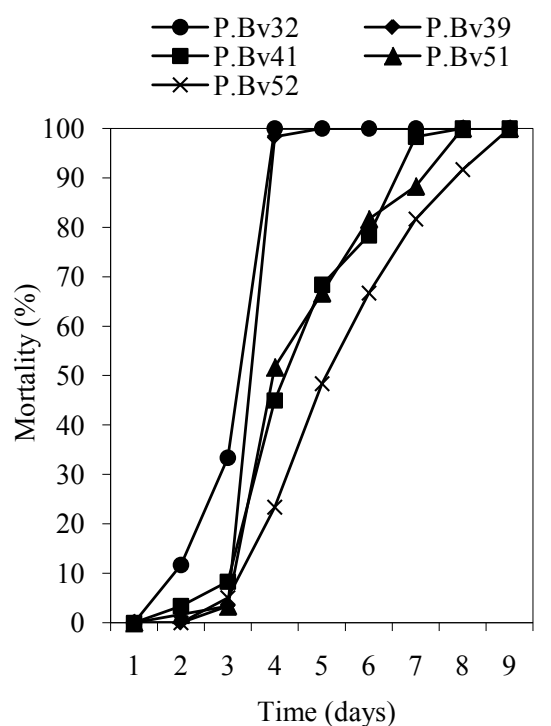

(b)

Figure 4. Adult mortality in Ceratitis capitata induced by Beauveria bassiana isolates 5 days after inoculation with different concentrations of conidia (a) (Least Significant Difference $=14.64)$; and mortality induced by the isolates at a concentration of $10^{8}$ conidia $/ \mathrm{mL}$ over time, incubated at $25^{\circ} \mathrm{C}(\mathrm{b})$.

$\left(10^{8}\right)$, the mortalities recorded for the same isolates were $100 \%, 100 \%, 68 \%, 67 \%$, and $58 \%$, respectively (Figure 4(b)). Concerning the lethal time $\left(\mathrm{LT}_{50}\right)$, and the lethal concentration $\left(\mathrm{LC}_{50}\right)$ that is required to kill $50 \%$ of the tested pest population, the results showed that the $\mathrm{LT}_{50}$ ranged from 3.91 to 5.6 days, depending on the isolate tested. The isolate P. Bv39 induced 50\% mortality after 3.91 days at the highest conidial inoculum concentration of $10^{8}$ conidia $/ \mathrm{mL}$ (Table 1 ). The lethal concentrations $\left(\mathrm{LC}_{50}\right)$ ranged from 3.8 to 10.5 as log concentrations (conidia/mL); the lowest concentration required (3.8) was recorded by the aggressive isolate $\mathrm{P}$. Bv32, while the highest concentration was recorded by the isolate P. Bv52 (Table 1).

Concerning the methodology of the B. bassiana application, there were significant differences inmortality between the two methods (Figure 5). The contact method resulted in higher rates of mortality than did the feeding method. The highest mortalities induced by the contact method ( $83 \%$ and $92 \%)$ were recorded by the B. bassiana isolates P. Bv32 and P. Bv39, respectively, 4 days after inoculation (Figure 5). 


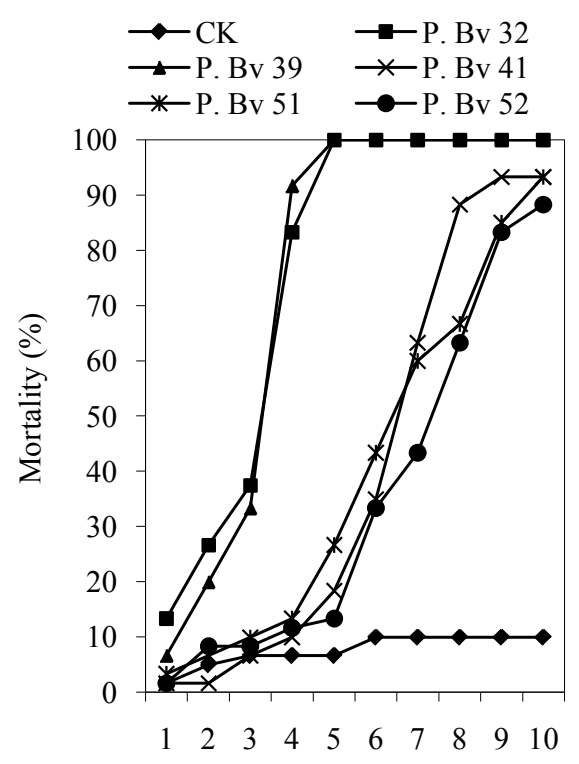

(a)

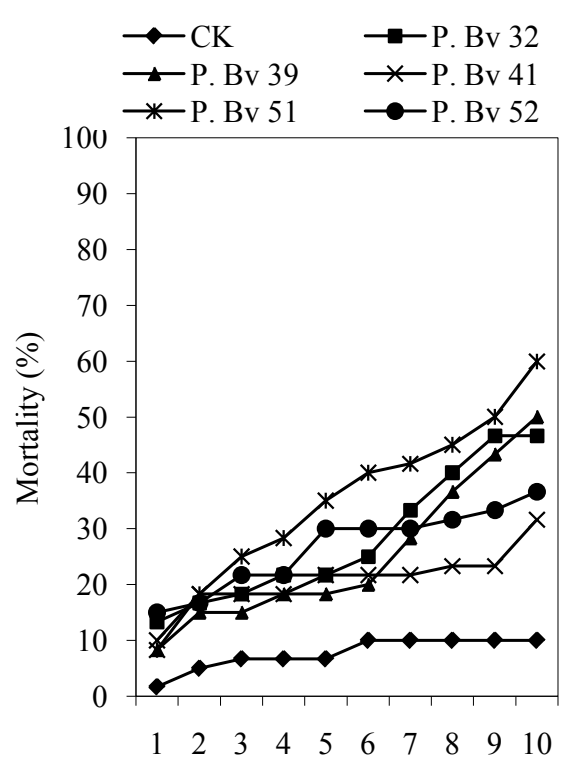

(b)

Figure 5. Effect of Beauveria bassiana (P. Bv32, P. Bv39, P. Bv41, P. Bv51, and P. Bv52) application method on adult Ceratitis capitata mortality: contact (a), and feeding (b) (Least Significant Difference $=16.9$ ).

Table 1. The LT50 and LC 50 values induced by Beauveria bassiana native isolates (P. Bv32, P. Bv39, P. Bv52, P. Bv41, and P. Bv51) on adult Ceratitis capitata flies.

\begin{tabular}{ccc}
\hline B. bassiana isolate & $\begin{array}{c}\text { LC50 } 5 \text { days post-inoculation } \\
(\text { log of conidia/mL concentration) }\end{array}$ & LT50 (days) at a concentration of $10^{8}$ conidia/mL \\
\hline P. Bv39 & 4.3 & 3.9 \\
P. Bv32 & 3.8 & 3.9 \\
P. Bv41 & 7.9 & 5.1 \\
P. Bv51 & 7.3 & 5.5 \\
P. Bv52 & 10.5 & 5.6 \\
\hline
\end{tabular}

Furthermore, the isolates P. Bv32 and P. Bv39 reduced peach infestations by $73 \%$ and $64 \%$, respectively, compared to the control. The average number of larvae per peach was 9 and 12 , respectively, compared to the control, which had 33 larvae per peach. No significant difference (LSD $=7.4, \mathrm{P} \leq 0.05)$ was found between the two isolates (Figure 6).

Under field conditions, the bioinsecticide treatment containing the B. bassiana isolate P. Bv32 was able to significantly reduce peach infestation with Medfly maggots by $25 \%$ compared to the control, and by $30 \%$ when combined with a low dose of the commercial insecticide Confidor ${ }^{\mathbb{B}}$ (Figure 7).

\section{Discussion}

The entomopathogenic fungus $B$. bassiana is the most common parasite of insects that has been isolated from soil, litter, and dead or moribund insects in nature [18]. In the current study, B. bassiana was recovered from soil samples collected from Palestinian agricultural fields using an improved semi-selective medium (GPA), amended with $90 \mu \mathrm{g} \cdot \mathrm{mL}^{-1}$ Dodine (GPAD) [20] [21]. Native B. bassiana isolates induced significant (58\% $100 \%$ ) mortality to adult $C$. capitata flies, depending on the isolate and inoculum concentration used. Similar results were obtained by Konstantopoulou and Mazomenos [22], who found that B. bassiana induced $85.6 \%$ mortality ina C. capitata population, but was less effective against Bactroceraoleae. Similarly, Munoz [23] evaluated the pathogenic potential of 16 strains of $B$. bassiana against adult $C$. capitataflies, and reported a mortality 


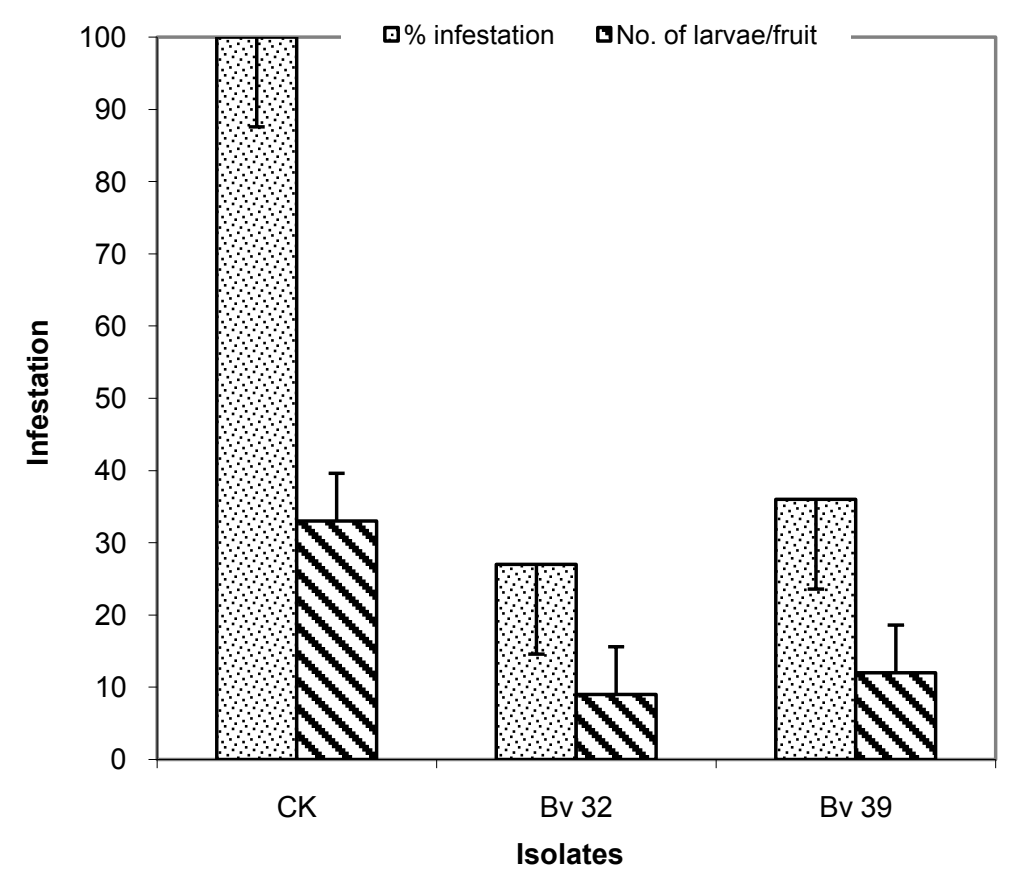

Figure 6. Infestation of peaches (\%) (LSD $=12.6)$ and the average number of Ceratitis capitata larvae per peach $(\mathrm{LSD}=7.4)$ after inoculation with the Beauveria bassiana isolates P. Bv32 and P. Bv39 at a concentration of $10^{8}$ conidia/mL.

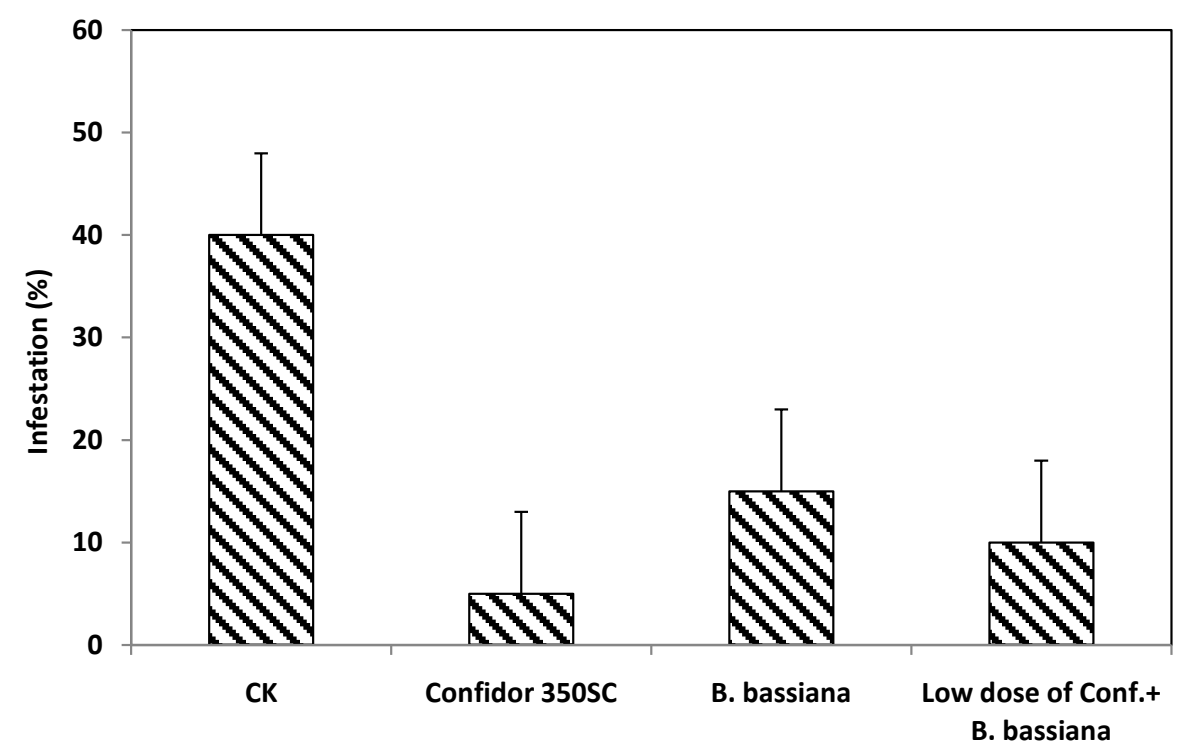

Figure 7. Effect of the Beauveria bassiana isolate P. Bv32 formulated for field applications at a concentration of $10^{8}$ conidia/mL, the insecticide Confidor ${ }^{\circledR} 350 \mathrm{SC}$ at the recommended dose, and a combination of a low dose of Confidor ${ }^{\circledR}$ and B. bassiana, on Ceratitis capitata field infestations of peaches $(\%)$ under field conditions (LSD $=8$ ).

range of 20\% - 98.7\%. In addition, Quesada-Moraga et al. [24] reported a mortality range of $30 \%-100 \%$ when a conidial suspension was used at a concentration of $10^{8}$ conidia $/ \mathrm{mL}^{-1}$.

The $C$. capitata mortality rate was correlated with the conidial concentrations tested. $\mathrm{LC}_{50}$ values ranged from 3.8 to 10.5 (as a log concentration) with obvious differences between $B$. bassiana isolates; the $\mathrm{LT}_{50}$ induced by the isolates ranged from 3.9 to 5.6 days. Similar results were obtained by Quesada-Moraga et al. [25], who found 
that lethal concentrations $\left(\mathrm{LC}_{50}\right)$ of the four most virulent isolates ranged from $4.9 \times 10^{5}$ to $2.0 \times 10^{6} \mathrm{cfu} / \mathrm{mL}$, with an estimated time to kill $50 \%$ of $C$. capitata ranging from 4.6 to 5.3 days. In addition, Mwamburi \& Miller [25] reported that the lethal concentrations of $34 \mathrm{~B}$. bassiana isolates that caused $50 \%$ mortality $\left(\mathrm{LC}_{50}\right)$ in adult house flies (Muscadomestica L.; Diptera, Muscidae) ranged between $10^{3}-10^{5}$ conidia/mL, and the lethal time $\left(\mathrm{LT}_{50}\right)$ values ranged between $0.44-1.3$ days.

The $B$. bassiana application method proved to be important; spraying inoculum (contact method) recorded high rates of adult $C$. capitata mortality. Differences in induced mortality rates between the isolates may have been related to differences in the conidial attachments onto the insect cuticle, modes of germination, or to the suppression of the host's immune system; similar results have been reported by Chandler et al., (1993). In addition, enzymes produced by B. bassiana isolates, such as extracellular proteases and peroxides, may have contributed to the variation in Medfly mortality that was observed [26] [27].

At the bioassay level, the B. bassiana isolates P. Bv32 and P. Bv39 applied at a concentration of $10^{8}$ conidia/mL on peaches significantly reduced the percentages of Medfly infestation by $73 \%$ and $64 \%$, respectively, compared to the control. Similar results were reported by Benuzzi and Santopolo [27], who suggested that $B$. bassiana might produce chemical compounds or fungal structures (e.g. hyphae) that reduce or inhibit Medfly oviposition. Moreover, repellent volatile cues could be produced by B. bassiana, but the effects of these compounds on oviposition behaviour in C. capitataare unclear [28]. In addition, it has been shown that B. bassiana produces metabolites that are repellent to insects (e.g. peramine) [29] [30].

Temperature dramatically influenced $B$. bassiana growth and development, with differences observed between the isolates. All the isolates failed to grow and develop at temperatures below $10^{\circ} \mathrm{C}$ and above $30^{\circ} \mathrm{C}$. There were differences observed in the optimal temperatures required for various stages of growth and development. The optimum temperature for mycelial growth was $30^{\circ} \mathrm{C}$ in most of the isolates, and the optimum range for sporulation and germination was $20^{\circ} \mathrm{C}-25^{\circ} \mathrm{C}$. Regarding their virulence, some $B$. bassiana isolates successfully grew over a wide range of temperatures (e.g. P. Bv32), but the majority grew in the range $25^{\circ} \mathrm{C}-30^{\circ} \mathrm{C}$. Similar results were found by Hallsworth and Magan [31], who reported that the lowest radial growth occurred at $15^{\circ} \mathrm{C}$ and $35^{\circ} \mathrm{C}$ in all the $B$. bassiana isolates tested, except for the isolate Bb-01, which ceased to grow at $35^{\circ} \mathrm{C}$. The optimum temperature for sporulation and germination was $20^{\circ} \mathrm{C}$ for $\mathrm{Bb}-01$ and $25^{\circ} \mathrm{C}$ for the remaining isolates. Furthermore, several investigators have reported that the optimum temperatures for $B$. bassiana mycelial growth, conidial germination, sporulation, and virulence are in the range $20^{\circ} \mathrm{C}-30^{\circ} \mathrm{C}$ [32]-[34].

\section{Conclusion}

In conclusion, the B. bassiana native isolate $\mathrm{P}$. Bv32 proved to be effective in controlling adult $C$. capitata flies in vitro, in vivo, and under field conditions, where it significantly reduced Medfly infestations in peaches that were treated with a mycoinsecticide formula alone, or in combination with the insecticide Confidor ${ }^{\mathbb{R}}$.

\section{References}

[1] Freidberg, A. and Kugler, A. (1989) Fauna Palestina, Insecta IV-Diptera: Tephritidae. Israel Academy of Sciences, Jerusalem, 210.

[2] Cayol, J.P., Causse, R., Louis, C. and Barthes, J. (1994) Medfly Ceratitis capitata Wiedemann (Dipt., Trypetidae) as a Rot Vector in Laboratory Conditions. Journal of Applied Entomology, 117, 338-343. http://dx.doi.org/10.1111/j.1439-0418.1994.tb00744.x

[3] Mustafa, T.M. and Abdul-Jabbar, S. (1996) Studies on Some Hosts of the Medfly Ceratitis capitata Wied. (Diptera: Tephritidae) in the Central Highlands of Jordan. Arab Journal of Plant Protection, 14, 91-95.

[4] Kheder, S.B., Trabelsi, I. and Aouadi, N. (2012) From Chemicals to IPM against Mediterranean Fruit Fly Ceratitis capitata, (Diptera: Tephritidae). In: Larramendy, M.L. and Soloneski, S., Eds., Integrated Pest Management and Pest Control-Current and Future Tactics, In Tech Europe, Rijeka, 668.

[5] Robinson, A.S. (2002) Genetic Sexing Strains in Medfly, Ceratitis capitata, Sterile Insect Technique Programmes. Genetica, 116, 5-13. http://dx.doi.org/10.1023/A:1020951407069

[6] Beris, E.I., Papachristos, D.P., Fytrou, A., Antonnatos, S.A. and Kontodimas, D.C. (2013) Pathogenicity of Three Entomopathogenic Fungi on Pupae and Adults of the Mediterranean Fruit Fly, Ceratitis capitata (Diptera: Tephritidae). Journal of Pest Science, 86, 275-284. http://dx.doi.org/10.1007/s10340-012-0468-4

[7] Ownley, B., Gwinn, K. and Vega, F. (2010) Endophytic Fungal Entomopathogens with Activity against Plant Patho- 
gens: Ecology and Evolution. BioControl, 55, 113-128. http://dx.doi.org/10.1007/s10526-009-9241-x

[8] Rehner, S.A. and Buckley, E. (2005) A Beauveria Phylogeny Inferred from Nuclear ITS and EF1- $\alpha$ Sequences: Evidence for Cryptic Diversification and Links to Cordyceps Teleomorphs. Mycologia, 97, 84-98. http://dx.doi.org/10.3852/mycologia.97.1.84

[9] Roberts, D.W. and St. Leger, R.J. (2004) Metarhizium spp., Cosmopolitan Insect-Pathogenic Fungi: Mycological Aspects. Advances in Applied Microbiology, 54, 1-70. http://dx.doi.org/10.1016/S0065-2164(04)54001-7

[10] Dhuyo, A.R. and Selman, B.J. (2007) Efficacy of Biocontrol Agents Combined with Insecticide against the Larger Grain Borer Prostephanus truncates (Horn.) (Bostrichidae: Coleoptera). Pakistan Journal of Entomology, 29, 57-62.

[11] Neves, P.M.O.J. and Hirose, E. (2005) Seleção de isolados de Beauveria bassiana para o controlebiológico da brocado-café, Hypothenemus hampei (Ferrari) (Coleoptera: Scolytidae). Neotropical Entomology, 34, 77-82. http://dx.doi.org/10.1590/S1519-566X2005000100011

[12] Gill, H.K. and Garg, H. (2014) Pesticide: Environmental Impacts and Management Strategies. In: Solenski, S. and Larramenday, M.L., Eds., Pesticides-Toxic Effects, Intech, Rijeka, 187-230.

[13] Vega, F.E. (2008) Insect Pathology and Fungal Endophytes. Journal of Invertebrate Pathology, 98, $277-279$. http://dx.doi.org/10.1016/j.jip.2008.01.008

[14] Gomez-Vidal, S., Lopez-Liorca, L.V., Jansson, H.B. and Salinas, J. (2006) Endophytic Colonization of Date Palm (Phoenix dactylifera L.) Leaves by Entomopathogenic Fungi. Micron, 37, 624-632. http://dx.doi.org/10.1016/j.micron.2006.02.003

[15] Posada, F. and Vega, F.E. (2005) Establishment of the Fungal Entomopathogen Beauveria bassiana (Ascomycota: Hypocreales) as an Endophyte in Cocoa Seedlings (Theobroma cacao). Mycologia, 97, 1195-1200. http://dx.doi.org/10.3852/mycologia.97.6.1195

[16] Quesada-Moraga, E., Landa, B.B., Munoz-Ledesma, J., Jiminez-Diaz, R.M. and Santiago-Alvarez, C. (2006) Endophytic Colonisation of Opium Poppy, Papaver somniferum, by an Entomopathogenic Beauveria bassiana Strain. Mycopathologia, 161, 323-329. http://dx.doi.org/10.1007/s11046-006-0014-0

[17] Zimmermann, G. (2007) Review on Safety of the Entomopathogenic Fungi Beauveria bassiana and Beauveria brongniartii. Biocontrol Science and Technology, 17, 553-596. http://dx.doi.org/10.1080/09583150701309006

[18] Feng, Z., Carruthers, R.I., Roberts, D.W. and Robson, D.S. (1985) Age-Specific Dose-Mortality Effects of Beauveria bassiana (Deuteromycotina: Hyphomycetes) on the European Corn Borer, Ostrinia nubilalis (Lepidoptera: Pyralidae). Journal of Invertebrate Pathology, 46, 259-264. http://dx.doi.org/10.1016/0022-2011(85)90067-9

[19] Thomas, K.C., Khachatourians, G.G. and Ingledew, W.M. (1987) Production and Properties of Beauveria bassiana Conidia Cultivated in Submerged Culture. Canadian Journal of Microbiology, 33, 12-20. http://dx.doi.org/10.1139/m87-003

[20] Shimazu, M. and Sato, H. (1996) Media for Selective Isolation of an Entomogenous Fungus, Beauveria bassiana (Deuteromycotina: Hyphomycetes). Applied Entomology and Zoology, 31, 291-298.

[21] Shin, T.Y., Choi, J.B., Bae, S.M., Koo, H.N. and Woo, S.D. (2010) Characterization of Beauveria bassiana MsW1 Isolated from Pine Sawyers, Monochamus saltuarius. Department of Agricultural Biology, College of Agriculture Life \& Environment Science, Chungbuk National University, Cheongju, 361-367.

[22] Konstantopoulou, M.A. and Mazomenos, B.E. (2005) Evaluation of Beauveria bassiana and B. brongniartii Strains and Four Wild-Type Fungal Species against Adults of Bactrocera oleae and Ceratitis capitata. BioControl, 50, 293305. http://dx.doi.org/10.1007/s10526-004-0458-4

[23] Munoz, R.J. (2000) Patogenicidad de Beauveria bassiana (Bals.) Bullí. sobre la mosca del mediterráneo, Ceratitis capitata (Wied.) en condiciones de laboratorio. Tesis de Licenciatura, Facultad de Ciencias Agricolas Univ. Aut de Chiapas, Huehuetan, $55 \mathrm{p}$.

[24] Quesada-Moraga, E., Maranhao, E.A.A., Valverde-Garcĺa, P. and Santiago-Alvarez, C. (2006) Selection of Beauveria bassiana Isolates for Control of the Whiteflies Bemisia tabaci and Trialeurodes vaporariorum on the Basis of Their Virulence, Thermal Requirements, and Toxicogenic Activity. Biological Control, 36, 274-287. http://dx.doi.org/10.1016/j.biocontrol.2005.09.022

[25] Mwamburi, L.A., Laing, M.D. and Miller, R.M. (2010) Laboratory Screening of Insecticidal Activities of Beauveria bassiana and Paecilomyces lilacinus against Larval and Adult House Fly (Musca domestica L.). African Entomology, 18, 38-46. http://dx.doi.org/10.4001/003.018.0106

[26] Bidochka, M.J. and Khachatourians, G. (1990) Identification of Beauveria bassiana Extracellular Protease as a Virulence Factor in Pathogenicity toward the Migratory Grasshopper, Melanoplus sanguinipes. Journal of Invertebrate Pathology, 56, 362-370. http://dx.doi.org/10.1016/0022-2011(90)90123-N

[27] Benuzzi, M. and Santopolo, F. (2001) Naturalis: Bioinsetticida a Base di Beauveria bassiana. Informatore Fitopa- 
tologico, 51, 61-64.

[28] Chandler, D., Heale, J.K. and Gillespie, A.T. (1993) Competitive Interaction between Strains of Verticillium lecanii on Two Insect Hosts. Annals of Applied Biology, 122, 435-440. http://dx.doi.org/10.1111/j.1744-7348.1993.tb04046.x

[29] Wright, J.E. and Chandler, L.D. (1992) Development of a Biorational Mycoinsecticide: Beauveria bassiana Conidial Formulation and Its Application against Boll Weevil Populations (Coleoptera: Curculionidae). Journal of Economic Entomology, 85, 1130-1135. http://dx.doi.org/10.1093/jee/85.4.1130

[30] Rowan, D.D., Dymock, J.J. and Brimble, M.A. (1990) Effect of Fungal Metabolite Peramine and Analogs on Feeding and Development of Argentine Stem Weevil (Listronotus bonariensis). Journal of Chemical Ecology, 16, 1683-1695. http://dx.doi.org/10.1007/BF01014100

[31] Hallsworth, J.E. and Magan, N. (2009) Water and Temperature Relations of Growth of the Entomogenous Fungi Beauveria bassiana, Metarhizium anisopliae, and Paecilomyces farinosus. Journal of Invertebrate Pathology, 74, 261266. http://dx.doi.org/10.1006/jipa.1999.4883

[32] Dimbi, S., Maniania, N.K., Lux, S.A. and Mueke, J.M. (2004) Effect of Constant Temperatures on Germination, Radial Growth and Virulence of Metarhizium anisopliae to Three Species of African Tephritid Fruit Flies. BioControl, 49, 8394. http://dx.doi.org/10.1023/B:BICO.0000009397.84153.79

[33] Parker, B.L., Skinner, M., Gouli, V. and Brownbridge, M. (2010) Impact of Soil Applications of Beauveria bassiana and Mariannaea sp. on Nontarget Forest Arthropods. Biological Control, 8, 203-206. http://dx.doi.org/10.1006/bcon.1997.0516

[34] Tefera, T. and Pringle, K. (2003) Germination, Radial Growth, and Sporulation of Beauveria bassiana and Metarhizium anisopliae Isolates and Their Virulence to Chilo partellus (Lepidoptera: Pyralidae) at Different Temperatures. Biocontrol Science and Technology, 13, 699-704. http://dx.doi.org/10.1080/0958315031000151756 